\title{
Health care worker's perception about the quality of health care at the outpatient department in Mwananyamala Hospital in Dar es Salaam, Tanzania
}

\author{
KUDRA KHAMIS ${ }^{1}$ and BERNARD NJAU ${ }^{1,2^{*}}$ \\ ${ }^{1}$ Kilimanjaro Christian Medical University College, Box 2240, Moshi, Tanzania \\ ${ }^{2}$ Kilimanjaro Christian Medical Centre, Box 3010, Moshi, Tanzania
}

\begin{abstract}
Background: Quality of care is a complex issue influenced by many factors. It is fundamental in assessing health care delivery in health facilities in developing countries. Health care workers' perceptions help policy makers and planners to identify bottlenecks in the system to improve utilisation and sustainability of health care services in the population. The objective of this study was to explore health care workers' perception about the quality of health care delivered at the outpatient department in Mwananyamala Hospital in Dar es Salaam, Tanzania.

Methods: A cross-sectional qualitative study was conducted from April to May 2013.

Results: Health care workers' mentioned extrinsic as well as intrinsic factors, which may influence the quality of health care services. Extrinsic factors included poor physical infrastructure, unavailability of medical equipment and/or essential drugs and poor staffing levels. Intrinsic factors mentioned were motivation for health care workers and workplace training opportunities.

Conclusion: Multiple factors influencing perceived quality of health care Mwananyamala hospital have been identified to include physical infrastructure, availability of medical equipment and essential medicines, staffing levels, remuneration and promotion.
\end{abstract}

Key words: Heath care workers, quality of health care, outpatient department, Tanzania

\section{Introduction}

Quality of health care is defined as a degree of performance in relation to a defined standard of interventions known to be safe and with the capacity to improve health within available resources (Murray \& Frenk 2000). In fact, quality of care is a complex issue influenced by many factors. Some elements in the quality of care are easy to define and measure, while others are more difficult (Donabedian, 1980). Certainly, the complexity of the concepts and their measurements should be considered whenever quality of care is been assessed, either in general terms or in specific levels of health delivery (Cole et al., 2005). It is imperative, therefore to agree on the elements that constitute quality of care prior to assessment of quality of health services (Donabedian, 1980).

Perceptions of health care workers (HCWs), towards quality of care at their respective workplaces have gained more attention in recent years. Evidence from several studies has shown that HCWs suggestions help policy makers and planners to identify bottlenecks in the health system, to improve utilisation and sustainability of health care services in the general population (Lantis et al., 2002; Manongi et al., 2006; Songstad et al., 2012). Indeed, obtaining HCW's views on the health services is a realistic tool to evaluate and improve the health system (Manongi et al., 2006; Songstad et al., 2012).

There is evidence that motivation theories and models may predict HCWs behaviours in a particular environment. For example a study by Hackman \& Lawler (1971) provides evidence that job characteristics can directly affect employee attitudes and behaviours at work. In

\footnotetext{
* Correspondence: E-mail: biesein2007@gmail.com
} 
addition, the job characteristics model posits that there are five "core " job dimensions (i.e., skill variety, task identity, task significance, autonomy, and feedback) that prompt three psychological status (i.e., experienced meaningfulness, experienced responsibility, and knowledge of results), which in turn leads to multiple beneficial personal and work outcomes such as internal work motivation, quality of work performance, job satisfaction, absenteeism, and turnover (Hackman \& Oldham, 1976). On the other hand, self-determination theory (SDT), which differentiates extrinsic motivation into types that differ in their degree of autonomy is imperative in achieving total job satisfaction through effective performance in the working environment (Gagné \& Deci, 2005).

The government of Tanzania, through the Ministry of Health and Social Welfare has recognised the importance of improving the quality of care through different approaches, such as Health Quality Improvement Framework, with an overall objective of improving the quality of health services, and well-being of all Tanzanians ( $\mathrm{MOH}, 2003$; MoHSW, 2011). Despite the governments' efforts to improve quality of care, the health service provision is constrained by a number of factors including poor infrastructure, unavailability of medicines and/or medical equipment and limited human resources for health $(\mathrm{MOH}, 2003$; Kruk \& Freedman, 2008; Juma \& Manongi 2009; Munga \& Mwangu, 2013). Due to these constraints, Tanzania has embarked on a process of implementing policy changes under a Health Sector Reform Strategy $(\mathrm{MOH}, 2003$, MoHSW 2008a,b). Central to the reforms is the decentralisation of health services in the country. Decentralisation is well documented as a key strategy, which empowers the local health authorities to be more independent and autonomous (WHO 2006; MoHSW, 2007, 2008; Munga \& Mwangu, 2013).

Despite these reforms, clients attending public health facilities still perceive low quality of care (Khamis \& Njau 2014). One of the key challenges in Tanzania, is insufficient human resources for heath, particularly in rural settings (Songstad et al., 2011; Penfold et al., 2013). In $2012 / 2013$ for example, the national average doctor ratio per 10,000 was 0.9 while the national average nurses/midwives per 10,000 populations was 4.9 (Mboera et al., 2015).

There is dearth of empirical evidence on perceptions' of HCWs towards improvement of quality of care in health facilities in Tanzania. This study therefore aimed to explore HCWs perceptions towards quality of care delivered at an outpatient department (OPD) in an urban health facility. Findings from this study will add knowledge to the literature by exploring how HCWs perceptions towards quality of care may assist in improving quality of care in the study setting.

\section{Materials and Methods}

\section{Study area and data collection}

A cross-sectional qualitative study was conducted at Mwananyamala Hospital from April to May 2013. Mwananyamala hospital is a public facility located in Kinondoni District in Dar es Salaam, Tanzania. At the time of data collection, Mwananyamala Hospital was attending to 1,500 to 1,700 patients per day (Mwananyamala Hospital 2010 unpubl.). Purposive sampling (Spencer et al., 2003; Singleton \& Straits, 2005), was employed to select 27 participants. Ten in-depth interviews were conducted with key informants (Five males; five females). Two focus group discussions (FGDs) were conducted including 17 participants (Eight males; nine females). Participants included were hospital administrators, clinicians and nurses working at the OPD who were present during the study period.

The semi-structured interviews and FGDs addressed perceptions about the quality of health services at the OPD. Interviews were conducted Kiswahili and tape-recorded in private settings convenient to the respondents, to ensure confidentiality and privacy.

\section{Data analysis}


All interviews and FGDs were transcribed verbatim and translated into English. A framework approach (Spencer et al., 2003, Singleton \& Straits, 2005), combining the use of ATLAS.ti and manual techniques guided the identification of key themes used to develop the thematic framework, which was systematically applied to sort the data. The texts were read repeatedly to identify major themes and each theme was broken down into concepts. Representative, verbatim quotes were selected to illustrate key findings.

\section{Ethical considerations}

Ethics approval was obtained from Kilimanjaro Christian Medical University College Ethics review committee. The respondents were informed of the purpose of the study and assured of confidentiality and their right to withdraw from the study.

\section{Results}

A total of 27 health workers participated in this study. Mean age of the participants were 37 years in males and 29 year in females. Of the participants, clinicians were 8, nurses 9 and administrators 10. During the analysis two main themes emerged and were categorised as i) Extrinsic factors (e.g. perceptions towards physical infrastructure, medical equipment and/or drugs and staffing levels, and; ii) intrinsic factors (e.g. perceptions towards salaries, allowances, promotions and workplace training opportunities).

\section{Perceptions about physical infrastructure, availability of equipment and staffing levels}

Health care workers perceived that the status of physical infrastructure, availability of medical equipment and staffing levels are key extrinsic factors influencing the delivery of quality of services. Generally, respondents were not satisfied with the current status of the hospital physical infrastructure because the buildings were dilapidated and unable to accommodate the increased number of patients seeking care at the OPD. "This hospital was designed to operate as a district hospital, but now it is upgraded to a Regional referral hospital, but we still have small buildings, which do not accommodate the number of our clients."(IDI 1).

Shortages of functioning medical equipment and/or essential medicines, delays in payment to the suppliers of drugs and equipment, and long procedures to request for out-ofstock medicines were perceived as factors impacting on the delivery of quality of care. Discussants mentioned how they experienced stock-outs of essential medical equipment such as syringes and laboratory reagents in the three weeks prior to the study. Participants in both FGDs and IDIs had this to say: "[...] lack of working medical equipment also causes the quality of care to be low, a person cannot work without proper equipment, and for example for the past three weeks we were out of stock of syringes and laboratory reagents" (Male FGDs; IDI 5.

In addition, participants observed that even the existing equipment was old and outdated. One respondent said: "Also the equipment, which we have is very old and outdated [...]" (IDI 6). Participants in the FGDs commented, "[...] at the OPD, the steriliser machine is very old and small and we have a lot of equipment to sterilise, this affects the quality of care since the patients have to wait for long periods of time to get treatment [...]" (Female FGDs).

Participants mentioned the main reason for stock-outs were similar to other public hospital. The stock-out was attributed to the fact that the hospital depends on the government's central Medical Stores Department (MSD) for all medical supplies and equipment. Delays in payments to the MSD were mentioned as a key reason for stock-out as illustrated in the following narrative: [...] we [hospital] get all of our medicines and medical equipment from MSD so sometimes the municipal/or the central government does not pay on time, and MSD delays the supply of drugs, equipment and reagents [...]" (IDI 3 ).

Long procedures including extensive paper work have to be followed to get new equipment or medicines once they are out of stock. This was mentioned as another factor likely 
to impact on quality of care. Two IDI respondents commented: "When you run out of stock there is a long procedure to be followed before receiving new stock of medical equipment and/or medicines. First you should write an order and submit it to the hospital main store through the administration [...]. It would be easy if we submit directly to the medical store to avoid the red tape procedures [...]" (IDI 7 ).

Participants raised the issue of understaffing as another factor that contributes to the low quality of care delivered at the OPD. "[...] OPD is like the reception area for all clients before they are taken to their respective clinics. So due to inadequate number of staff we cannot attend them in the standard which is needed [...]" (Male FGDs). Another participant commented: "I know I should spend at least ten minutes to listen to the clients during consultation, but I cannot do that because we are very few and the number of clients is high and we must attend all of them [...]" (Male FGDs). Participants also commented that because of shortage of staff the workload is increasing and clinician: patient ratio is high: "Client numbers are increasing day by day, so you find yourself doing the job of three clinicians" (IDI 1).

Patients who bypass the referral systems in their respective catchment areas and decide to seek care at the hospital, was mentioned by HCWs as an explanation of the increasing number of patients at the OPD, and hence an impact on quality of care. This was well described in a following narrative: "[...] many clients do not comply with the referral systems and hence bypassing other health facilities and coming here. When we ask them for the reasons, they say that the quality of care in this hospital is high compared to other lower health facilities [...]" (IDI 2).

\section{Perceptions on intrinsic factors influencing quality of care}

Across all the FGDs and IDIs, participants mentioned multiple factors contributing to low morale. Low salaries in public hospitals, discrimination in payments of allowances, lack of timely promotion and limited opportunities for upgrading skills were mentioned as intrinsic motivation factors influencing perceptions towards quality of care. Participants perceived that HCWs working in public hospitals are paid low salaries compared to their counterparts in private hospitals. This observation was illustrated in the following narrative: "We are working in an infectious area [hospital], whereby we are exposed to different infectious diseases but our salaries are lower compared to our fellows in private hospitals (Female FGDs). Apart from low salaries, participants also discussed discrimination in payments of allowances due to HCWs. One nurse said: "[...] there is no motivation at work in a public hospital. For example, the Government's guidelines on allowances stipulate that all HCWs should be paid allowances like mid-month, house and transport allowances. But house allowances are paid only to the doctors. Nurses are not paid. This is not fair since all of us work under the same difficult conditions [...]" (Female FGDs).

Participants mentioned lack of timely promotion of HCWs of different cadres as a factor influencing quality of care. Participants were aware of their right to be promoted after every three years as stipulated by the government regulations and that a promotion was to be accompanied by salary increment. One female nurse officer explained: "It is very discouraging since I have been working for more than 7 years but I have been promoted only once" (Female FGDs). Another participant added: "[...] To be promoted nowadays depends on your level of education. If you have a bachelor or master degree then you are more likely to be promoted. The government does not consider those who have worked for long if they do not have degrees]. This is very disappointing [...]" (IDI 8).

Limited opportunities to attend courses to upgrade skills for various reasons were also mentioned by some participants. A clinician illustrated this as follows: "[...] to get permission to go for further studies are very difficult nowadays because of shortages of staff. Because before you submit your application you are required to must contact the authorities for permission to apply. If there are many staff members who have submitted similar applications for training, you will not get permission. This is very discouraging, since every person has his/her own career development plan, so when you're denied permission it ruins all your plans [...]" (Male FGDs). 
Across all FGDs and IDIs, participants indicated their satisfaction with the hospital management, particularly in decision-making, on-the-job training and an existing workers organisation. The following narratives emphasise this: "We are happy the hospital management involves us in decision-making. We have departmental meetings where we provide our views; also we have a worker's union known as Tanzania Local Government Workers Unit (TALGWU) [...]" (IDI 5). "[...] we also have on-the-job training sessions - all staff are undergoing health information system training (Female FGDs).

\section{Discussion}

The health workers interviewed in this study outlined multiple factors, which might influence the quality of health services at the OPD in Mwananyamala Hospital. These included extrinsic factors namely physical infrastructure, availability of equipment and/or medicine and staffing levels. Participants also mentioned intrinsic factors, which are related to low salaries, allowances, promotions and training opportunities at the workplace. Health workers also expressed their concern about the current status of the buildings at the OPD. It was clear that the existing buildings were dilapidated. The most probable explanation is that the hospital was recently upgraded from a district to the level of a regional referral hospital, without renovation of the old buildings, and hence is unable to accommodate the increasing number of daily patients. This finding is consistent with a previous study done in two other hospitals in Dar es Salaam, Tanzania (Kagashe \& Rwebangila, 2011).

The perceived lack of essential medical equipment and/or drugs observed by discussants is crucial, because it is an important factor influencing quality of health services observed in several studies in other settings (Forster et al., 2006; Assefa et al., 2010; Khori et al., 2012; Penfold et al., 2013). Discussants highlighted the delay in payments to suppliers as a factor contributing to the shortage of medical equipment and essential medicines. Furthermore, respondents cited the cumbersome procedures required to replenish out-of-stock drugs at the OPD. In the Tanzanian health system, all pharmaceuticals and medical equipment are procured and distributed using a publicly run Medical Stores Department (Kagaruki et al., 2013). Studies have observed that the monopolistic nature of such public institutions contribute to poor quality of health services (Soeters et al., 2006; Cameron et al., 2009; Yadav, 2010). However, benefits of economies of scale and regulatory issues are associated with this procurement approach (WHO 2004, 2010). This dilemma between the disadvantages of a monopolistic government-controlled medical store versus the advantages of economies of scale and regulatory issues raises the need for further research.

In this study, participants perceived that the hospital was understaffed according to the national guidelines for staffing levels $(\mathrm{MoH}, 1999)$. This perception was substantiated by an observation that the hospital had a shortage of 171 staff of all cadres, which may have an impact on the hospital daily activities (data not shown). The consequences of the staff shortages include short consultation times and increased workload. This observation is consistent with studies elsewhere (Forster et al., 2006; Maestad et al., 2010; Penfold et al., 2013).

Another factor expressed by participants in this study related to increased workload was the bypassing of the referral system. Participants observed that many patients attending the OPD did not come from the hospital's geographical catchment area. This observation highlights the increasing problem of patients' self-referral which bypasses the established referral system $(\mathrm{MoH}, 2003)$. Studies to evaluate the cost-effectiveness and efficiency of the current referral system with regard to equity in access and utilisation may help to strengthen a functional referral system at all levels (Manongi et al. 2006).

In this study participants discussed several factors, which contribute to low morale, which impacts on the quality of health services. It is well documented that poor intrinsic motivation among health workers particularly in the public health sector is an obstacle to 
service delivery (Ryan \& Deci 2000; Leonard \& Masatu 2009; Songstad et al., 2011). Low salaries particularly in public health facilities were mentioned by most participants as a key factor contributing to poor quality of care. The emphasis placed on financial aspects such as salary level and extra allowances affirm the importance of financial gain as vital for full internalization of the extrinsic motivation (Leonard \& Masatu 2009; Maestad et al.. 2010). While proponents of monetary incentives have argued that financial gain, such as increased salaries are effective motivators, it is imperative to note that there can be a "hidden-cost", such as decreased intrinsic motivation in such monetary incentives (Ryan \& Deci, 2000; Leonard \& Masatu, 2009).

In this study some participants raised concerns regarding discrimination in payments of extra allowances particularly between doctors and nurses. This observation raises concerns about inter-relationship dynamics between doctors and nurses in this setting. It is imperative for the hospital management to address this to create a harmonious working environment, a key component to improve quality of care at Mwananyamala Hospital. In fact, the job characteristic model emphasizes that a harmonious working environment that promotes satisfaction of the three basic psychological states will enhance employees' internal motivation and full internalization of extrinsic motivation, leading to favourable work outcomes such as quality of care (Hackman \& Oldham, 1976).

Our study indicates that health workers perceived untimely promotions as a key factor to poor intrinsic motivation. Health workers in this setting are aware of their right to promotion every three years, but expressed their disappointment regarding delays in their promotions. Their concerns about lack of promotion, which lead to an increase in salaries, must be seen in the context of low incomes (Songstad et al., 2011). It is important for the hospital management to address this issue, in line with the self-determination theory, which emphasizes the importance of making extrinsic rewards such as higher pay and promotion clearly contingent upon effective performance (Gagne' \& Deci 2005).

Finally, health care workers expressed satisfaction with involvement in decision-making, participation in on-the-job training and the existing worker's organisation. This is in line with other studies, which observed that health workers also emphasised non-financial aspects of working conditions as vital for motivation and underlines the need to combine financial and non-financial incentives to motivate health care workers and hence improve quality of care (Kruk \& Freedman, 2008; Lehmann et al., 2008; Leonard \& Masatu, 2009; Maestad et al., 2010; Sonstad et al., 2011; Huicho et al., 2012; Manongi et al., 2014). This observation underscores the importance of involving health workers in the daily management of a health facility.

In conclusion, multiple factors influencing perceived quality of health care Mwananyamala hospital have been identified to include physical infrastructure, availability of medical equipment and essential medicines, staffing levels, remuneration and promotion.

\section{Acknowledgements}

We gratefully acknowledge all health care providers who participated in this study. We also thank the local health authorities who provided permission to conduct this study at Mwananyamala Hospital. Lastly, we would like to thank Ms. Michelle Galloway for her professional editing of the manuscript. 


\section{References}

Assefa , F., Moses, A. \& Johannes, M. (2010) Assessment of client's satisfaction with health care service delivered at Jimma University specialized hospital. Ethiopian Jounal of Health Science 21(2).

Cameron, A., Ewen, M., Ross-Degnan, D., Ball, D. \& Laing, R. (2009) Medicine process, availability,and affordability in 36 developing middle-income countries: a secondary analysis. Lancet 373, 240-249.

Cole, B.L., Shimkhada, R., Fielding, J.E., Kominski, G. \& Morgenstern, H. (2005) Methodologies for realizing the potential of health impact assessment. American Journal of Preventive Medicine 28, 382-389.

Donabedian, A. (1980) Exploration in Quality Assessment and Monitoring. Volume I: Definition of Quality and Aprroches to its Assessment. University of Michigan, Health Administration Press.

Forster , D., McLachlan, H., Yelland, J., Rayner, J., Lumley, J. \& Davey, M.A. (2006) Staffing in postnatal units: is it adequate for the provision of quality care? Findings from a statewide review of postnatal care in Victoria, Australia. BMC Health Services Research 6: 83.

Gagne', M. \& Deci, L.E. (2005) Self-determination theory and work motivation. Journal of Organizational Behavior 26, 331-362.

Hackman , R.J. \& Lawler, E.E. (1971) Employee reactions to job characteristics. Journal of Applied Pschology Monograph 55, 259-286.

Hackman , R.J. \& Oldham, G.R. (1976) Motivation through the design of Work: test of a Theory. Organizational Behavior and Human Performance 16, 250-279.

Huicho, L., Miranda, J.J., Diez-Canseco, F., Lema, C., Lescano, A.G., Lagarde, M. \& Blaauw, D. (2012) Job preferences of nurses and midwives for taking up a rural job in Peru: a discrete choice experiment. PLOS ONE 7 (12): e50315.

Juma, D. \& Manongi, R. (2009) User's perception of outpatient quality of care in Kilosa district hospital in central Tanzania. Tanzania Journal of Health Research 11, 196-204.

Kagaruki, G., Kimaro, H.C., Mboera, L.G. (2013) Factors affecting utilization of evidence based health information system for effective supply chain of essential medicine in Tanzania: a case study of Mbeya Region. Journal of Informatics in Developing Countries 7, 62-75

Kagashe , G. \& Rwebangila, F. (2011) Patent's satisfaction with health care service provided at HIV clinics at Amana and Muhimbili hopsital in Dar es Salaam. African Health Science 11, 60-66.

Khamis, K. \& Njau, B. (2014) Patients' level of satisfaction on quality of health care at Mwananyamala hospital in Dar es Salaam, Tanzania. BMC Health Services Research 14:400.

Khori , V., Changizi, S. \& Biuckians, E. (2012) Relationship between consultation length and rational prescribing of drugs in Gorgan City, Islamic Republic of Iran. Public Medicine 18, 480-486.

Kruk, M.E. \& Freedman, L.P. (2008) Assessing health system performance in developing countries: A review of literature. Health Policy 85, 263-276.

Lantis , K., Green, C. \& Stephanie, J. (2002) Providers and quality of care. New Perspectives on Quality of Care 3: 2-8.

Lehmann, U., Dieleman, M. \& Martineau, T. (2008) Staffing remote rural areas in middle- and low-income countries. A literature review of attraction and retention. BMC Health Services Research 8: 19.

Leonard, K.L. \& Masatu, M.A. (2009) Proffesionalism and know-to-do gap: Exploring intrinsic motivation among health workers in Tanzania. Health Economy 19, 1461-1477.

Maestad, O., Torsvik, G. \& Aakvik, A. (2010) Overworked? On the relationship between workload and health care performance. Journal of Health Economy 29, 686-698. 
Manongi, R., Mushi, D., Kessy, J., Saria, S. \& Njau, B. (2014) Does training on performance based financing make a difference in performance and quality of health care delivery? Health care provider's perspective in Rungwe Tanzania. BMC Health Services Research 14:154.

Manongi, R.N., Marchant, T.C. \& Bygbjerg, I.C. (2006) Improving motivation among primary health care workers in Tanzania: a health workers perspective. Human Resources for Health 4: 6.

Mboera, L.E.G., Ipuge, Y., Kumalija, J. Rubona, C.J., Perera, S., Masanja, H. \& Boerma, T. (2015) Mid-term review of national health plans: an example from the United Republic of Tanzania. Bulletin of the World Health Organization 93, 271-278.

MoH (1999) Staffing Levels for Health Facilities/Institutions. United Republic of Tanzania, Ministry of Health. Dar es Salaam,Tanzania.

MOH (2003) Tanzania National Health Policy. The United Republic of Tanzania, Ministry of Health. Dar es Salaam, Tanzania.

MoHSW (2007) Primary Health Services Development Programme 2007-2017. United Republic of Tanzania, Ministry of Health and Social Welfare. Dar es Salaam,Tanzania.

MoHSW (2008a) Health Sector Strategic Plan III July 2009-June 2015. United Republic of Tanzania, Ministry of Health and Social Welfare and Prime Minister's Office. Dar es Salaam, Tanzania.

MoHSW (2008b) Human Resource for Health Strategic Plan 2008-2013. United Republic of Tanzania, Ministry of Health and Social Welfare. Dar es Salaam,Tanzania.

MoHSW (2011) The Tanzanian Health Care Quality Improvement Framework. United Republic of Tanzania, Ministry of Health and Social Welfare. Dar es Salaam,Tanzania.

MoHSW (2013) Human Resource for Health Country Profile 2012/2013. United Republic of Tanzania, Ministry of Health and Social Welfare. Dar es Salaam,Tanzania.

Munga, M.A. \& Mwangu, M. (2013) Comprehensive health workforce planning: reconsideration of the primary health care approach as a tool for addressing the human resource for health crisis in low and middle income countries. Tanzania Journal of Health Research 15, 1-16.

Murray, C. \& Frenk, J. (2000) World Health Report 2000: a step towards evidence-based health policy. Lancet 357, 1698-1700.

Penfold, S., Shamba, D., Hanson, C., Jaribu, J., Manzi, F., Marchant, T., Tanner, M., Ramsey, K., Schellengberg, D. \& Schellenberg, J.A. (2013) Staff experiences of providing maternity services in rural southern Tanzania- a focus on equipment,drug and supply issues. BMC Health Services Research 13: 61.

Ryan, R.M. \& Deci, E.L. (2000) Intrinsic and extrinsic motivations: Classic definitions and new directions. Contemporary Education Psychology 25, 54-57.

Singleton, R. A. and B. C. Straits (2005). Approches to Social Research. New York,USA., Oxford University Press, Inc.

Soeters, R., Habineza, C. \& Peerenboom, P. (2006) Performance-based financing and changing the district health system: experience from Rwanda. Bulletin of the World Health Organization 84, 884-889.

Songstad, N.G., Lindkvist, I., Moland, K.M., Chimhutu, V. \& Blystad, A. (2012) Assessing performance enhancing tools: experiences with the open performance review and appraisal system (OPRAS) and expectations towards payment for performance(P4P) in public sector in Tanzania. Globalization and Health 8, 1-20.

Songstad, N.G., Rekdal, O.B., Massay, D.A. \& Blystad, A. (2011) Perceived unfairness in working conditions: The case of public health services in Tanzania. BMC Health Services Research 11: 34 .

Spencer, L., Ritchie, J., O'Connor, W. (2003) Carrying out qualitative analysis. Qualitative Research Practice: a Guide for Social Science Students and Researchers. J. Ritchie and J. Lewis. London/Thousand Oaks,CA/New Delhi, Sage Publications,pp. 219-62. 
WHO (2004) Equitable access to essential medicines: a framework for action (WHO Policy Perspectives on Medicines No 8). Geneva,Switzerland., World Health Organization.

WHO (2006) The World Health Report, Working together for health. World Helath Organization, Geneva,Switzerland.

WHO (2010) The WHO Prequalification Project. World Health Organization, Geneva,Switzerland. Yadav , P. (2010) In-country supplies chains. Global Health 5, 18-20. 